\title{
AGAINST ARTIFACTUAL EPISTEMIC PRIVILEGE
}

\author{
VÍCTOR M. VERDEJO \\ Department of Logic and Moral Philosophy \\ Faculty of Philosophy \\ University of Santiago de Compostela \\ vmverdejo@gmail.com
}

\begin{abstract}
SUMMARY: The deep intentional roots of artifacts and artifactual kinds seem to give intuitive as well as philosophical support to a form of epistemic privilege for makers regarding the objects they create. In this paper, I critically examine the thesis of epistemic privilege for artifact creators and present a counterexample based on anti-individualism. Several objections to the counterexample are considered and responded to. I conclude that, if anti-individualism is true, then the alleged epistemic privilege of creators of artifacts is either false or an explanatorily idle label. I argue, finally, that even if anti-individualism forces us to reject epistemic privilege for artifact kinds, these kinds may exhibit metaphysical and semantic mind-dependence, something that would keep them still distinctly apart from natural kinds and leave their essentially intentional nature untouched.
\end{abstract}

KEY WORDS: author, creation, concept possession, anti-individualism, mind-dependence

RESUMEN: Las profundas raíces intencionales de los artefactos y sus tipos parecen apoyar intuitiva y filosóficamente una forma de privilegio epistémico de los hacedores con respecto a los objetos que crean. En este artículo examino críticamente la tesis del privilegio epistémico para los creadores de artefactos y presento un contraejemplo basado en el antiindividualismo. Se consideran diversas objeciones a las que se da respuesta. Concluyo que si el antiindividualismo es verdadero, entonces el supuesto privilegio epistémico de los creadores de artefactos o bien es falso, o bien, una etiqueta explicativamente vacía. Defiendo, por último, que incluso si el antiindividualismo nos fuerza a rechazar el privilegio epistémico para tipos artefactuales, estos tipos aún pueden exhibir dependencia mental, tanto semántica como metafísica, algo que los continuaría distinguiendo de los tipos naturales y dejaría intacta su esencial naturaleza intencional.

PALABRAS CLAVE: autor, creación, posesión de conceptos, antiindividualismo, dependencia mental

According to a standard, baseline definition (e.g. Baker 2004; Dipert 1995; Hilpinen 2008; Thomasson 2007), artifacts are objects intentionally made or produced for a certain purpose. If artifacts are so intentionally made, it is only to be expected that artifact creators, whether they are creators of a new artifact or reproducers of an extant kind of artifact, must possess the requisite intentions. Indeed, it is certainly plausible that the very existence of genuine artifacts requires that there are (or there were) authors of them with the appropriate intentions. Standard intuitions therefore provide support to 
the following requirement for genuine artifactuality. For any object $O$, and author $A$, Authorship (A):

\section{(A)}

If $O$ is a genuine artifact, then there is an $A$ who has (or has had) the intention to create something of the $O$-sort.

The converse of (A) is patently not true. That there is an $A$ who has (or has had) the intention to create something of the $O$-sort is not a sufficient condition for $O$ to be a genuine artifact. At a minimum, the process by which $A$ realizes his or her intention to create $O$ must be satisfactorily accomplished. Nonetheless, it is hard to undermine the idea that $(\mathrm{A})$ expresses a necessary requirement for artifactuality. Here I wish to join the philosophical consensus in taking (A) to constitute such a necessary condition. ${ }^{12}$ However, I will be defending that a natural epistemological interpretation of this requirement is patently mistaken.

(A) demands creative intentions regarding $O$ for $A$, if $O$ is a genuine artifact. But that is only possible if $A$ fulfils whatever conditions are required for a subject to have the required intentions. Among such conditions one finds, no doubt, the conditions for having the concept of an $O$-sort of thing. Obviously, one has no intentions about things one cannot think about. And thinking about $O$ requires that one possesses or has the target $O$-concept. The notion of concept possession at hand is of a theoretically neutral sort and just refers to

${ }^{1}$ (A) is very much a matter of course among philosophers of technology, even if its importance may be downplayed by stressing the etiological or material aspect (e.g. Houkes and Meijers 2006; Houkes and Vermaas 2009; Vaccari 2013) and even the mind-independent character (e.g. Elder 2007) of artifactuality. However, as Vermaas and Houkes have pointed out, even "[a]n etiological theory for the technical [artifactual] domain appears to be intentionalist, because the causal histories of artifacts necessarily involve intentional behaviour of agents" (Vermaas and Houkes 2003 , p. 271). On the other hand, there is much controversy regarding what kind of intention is distinctive of artifactuality. Is it an intention essentially involving an intended function, or perhaps other intended (structural, shape, perceptible or recognitional) features? These questions go clearly beyond the scope of this paper.

${ }^{2}$ In this paper, the terms "creator", "maker", "producer" or "author" are used interchangeably. It is not clear that these terms are correctly so used in every context. Note, however, that the primary focus of the discussion to follow will be on cases of genuine authorship, and hence, cases in which it is clear that authors of $X$ are not merely agents causally involved in the production of $X$-just as, for instance, Harry could be claimed to be causally involved in the production of carabiners in the Acme Carabiner Factory (Kornblith 2007, p. 145) without being an author in this sense (cf. Thomasson 2007, p. 66). 
the capacity to think of $O$ s or of whatever falls under the concept of $O$ (cf. Fodor 1998, 2004; Davis 2005). It follows from this that (A) entails Possession (P) for any author $A$ and object $O$ :

If $O$ is a genuine artifact, then there is an $A$ who has (or has had) the concept of $O$.

As it happens, the aforementioned natural interpretation of (A), the one targeted in this paper, goes clearly beyond $(\mathrm{P})$. It is natural to suppose, as some philosophical circles have actually supposed, that (A) leads to a further requirement on the part of the corresponding authors. In particular, these authors, when they are authors of genuine artifacts, must (not only possess the relevant concepts but furthermore) have some sort of epistemic privilege about the artifacts they create. The intuitive idea is that the makers of an $X$ must know in a privileged and authoritative way what $X \mathrm{~s}$ are. After all, it really does seem plausible that authors of $X \mathrm{~s}$ must have a special knowledge about what they are doing when making an X. Otherwise, who would? In a more philosophically precise vein, the idea is that concepts that authors exhibit in their creative intentions must be largely correct concepts of the relevant artifacts. ${ }^{3}$ In fact, this is a usual tenet in the philosophical reflection on artifacts. It is closely related to the thesis that creative intentions determine artifact individuation (e.g. Hilpinen 1992; Bloom 1996). But it is Amie Thomasson (2003, 2007) who has provided the most explicit statements of the view. For ease of exposition, I will focus on Thomasson's developments. In

${ }^{3}$ Of course, in order for $S$ to have a largely correct concept $C$ of $O, S$ must first have $C$, where to have $C$ is fundamentally a psychological matter and to have a largely correct $C$ involves the (possibly privileged) knowledge that $S$ has of $O$. In this paper, I aim to show that in the case of artifactual concepts of creators (just as in the case of the vast majority of concepts), the converse of this claim is not true: that is, that from the fact that $S$ has a concept $C$ of $O$, it does not follow that $S$ has a largely or substantially correct $C$ of $O$, at least not if this is supposed to ground a genuine form of epistemic privilege. Note further that, although the present issue is about (privileged) knowledge of an artifactual object $O$, it is very much not about (privileged) self-knowledge of the content of a concept $C$ of $O$. All parties in this debate -including notably the anti-individualist (Burge 1988) - can agree that $S$ always knows the content of her $C$ of $O$. However, the sense in which one has (privileged) self-knowledge of the content of one's concept $C$ of $O$ is completely orthogonal to the sense in which one may have (privileged) knowledge about $O$ 's nature: I may be infallibly right about the content of my concept water and have no knowledge, let alone a privileged knowledge, about the (chemical) nature of the substance. 
her 2003 paper, Thomasson distinguishes strict artifactual kinds and loose artifactual kinds, depending on whether artifacts are allowed or not to undergo great changes over a period of historical development. Even for loose artifactual kinds, Thomasson contends that "if a[n artifact of kind] $K$ exists, there cannot be universal ignorance of $K$-relevant features; someone (at least the maker) must have a substantive concept of $K \mathrm{~s}$, and that thing must largely fulfill that concept" (Thomasson 2003, p. 602). The concept that figures in the maker's intention to produce an artifact of kind $K$ must therefore be a "substantive (and substantively correct) concept of what a $K$ is" (Thomasson 2007, p. 59). As a consequence of this tight relation between artifacts and substantively correct concepts of them, certain forms of epistemic privilege and immunity follow.

Thus the sense in which these artifacts and artifactual kinds are human creations does have important consequences for their metaphysics, and for our epistemic relation to them - consequences that mark them as importantly different from the objects and kinds of the natural sciences. In the former but not the latter case, the mere existence of objects of that kind entails that there is substantive knowledge of the kind's nature: their existence is not independent of human knowledge of them. And makers of artifacts are (as such) guaranteed certain forms of immunity from massive error about the objects of their creation, whereas scientists are not guaranteed a similar freedom from error about their objects of study. (Thomasson 2007, pp. 63-64)

As we will see in short, Thomasson might have been clearer than she actually has been about what it means to have a "substantive" or "substantively correct" concept ${ }^{4}$ of (and hence epistemic privilege about) an artifact or artifactual kind. As in many other cases of philosophical scrutiny, there is an ambiguity here between a strong and a weak reading. However, at the end of the path that I propose to follow the difference between a weak and a strong reading of Thomasson's position will not really matter. In particular, I will be arguing that, in spite of its intuitive plausibility, not even the weak reading of Thomasson's view can be sustained. At least not if one gives any credence to an anti-individualistic view about concept

\footnotetext{
${ }^{4}$ Thomasson $(2003,2007)$ refers to "substantive", "substantively correct" and "largely correct" "concepts", "notions" or "ideas" of artifacts in a clearly interchangeable way to spell out the nature of artifactual epistemic privilege. In any case, it must be borne in mind that this is an epistemological notion regarding the objects to which the relevant concepts apply (see fn. 3).
} 
possession, one that is the common philosophical ground at least since Burge's (1979) seminal contribution. More precisely, I will be defending that, if one accepts that what concepts subjects have is, at least in part, a matter of the relations that these subjects bear to their (physical or social) environment, then the thesis that authors of artifacts have a privileged knowledge about the objects they create is either false, or, as one says, an explanatorily idle label. This is so even if, as (A) conveys, authors of artifacts must have the concept of the objects they create. Let us now make fully explicit what kind of epistemic privilege will be assessed in this paper.

\section{Artifactual Epistemic Privilege}

I have said that Thomasson's considerations may be interpreted as involving either a strong claim or a weak claim about the substantive (or substantively correct) character of the concepts of makers of artifacts. In particular, the substantive character of the concepts in question may amount to the subject's possessing knowledge that either:

1) is definitive of the specific features relevant to being an artifact (of a certain kind),

or

2) is definitive of the general sorts of features relevant to being an artifact (of a certain kind).

The expression "being definitive of" is Thomasson's own (cf. Thomasson 2007). I will be assuming that "being definitive of" can be substituted by "being determinative of" and hence, simply by "determining". Following this interpretation, to say that a substantive concept (that a subject has) is definitive of the specific features or sorts of features of the target artifactual objects is simply to say that it involves knowledge that (fully) determines such specific features or sorts of features of artifactual objects. Now, Thomasson is clearly ambiguous between 1) and 2). Sometimes she seems to be concerned with a defense of epistemic privilege along the lines of 1), according to which, the "[...] makers" concepts must be definitive of the specific features relevant to membership in artifact kinds" (Thomasson 2007 , p. 60). At some other points, she seems to hold the weaker claim 2) and hence the thesis that the author of an artifact "must have a substantive idea of what sort of a thing it is she intends to 
create (say a $K$ )" (Thomasson 2007, p. 60). This may raise some exegetical problems but we can put them aside for present purposes. I will focus the discussion to follow on 2). I shall argue that, if anti-individualism is correct, the kind of knowledge required for artifactuality does not accord with 2). Since I will be assuming that a substantial version of anti-individualism is true, the advanced line of reasoning runs to the conclusion that we should give up on the thesis of the epistemic privilege of artifact makers. And since 2) is clearly weaker than 1), the presumption shall be that the thesis of epistemic privilege must be abandoned on either reading.

For present purposes, I will be assuming the truth of anti-individualism as a thesis about concept or thought possession without providing or articulating the general theory that underlies or undergirds such a thesis. ${ }^{5}$ We may state the target thesis as follows, for any subject $S$ :

What concepts $S$ has is (at least in part) a matter of what relations $S$ bears to the (social or physical) environment.

(AI) is, it must fairly be noted, not free of controversy. However, one version or other of (AI) is the received view in much of the current philosophical developments about the mental. These include accounts of self-knowledge (Burge 1988; Brown 2000, 2004), perception and representation (Burge 2010; Silins 2012), collective or cooperative cognition (Heal 2013), testimony (Goldberg 2007, 2009) or computationalism (Rescorla 2013), among others. This is why the analysis of (AI) and the consequences it has in relation to the alleged epistemic privilege of authors is important and interesting in its own right, whether or not we ultimately come up with a theory that articulates in detail the basis of such a thesis and, for that matter, whether or not this thesis ultimately turns out to be true. Note, on the other hand, that (AI) is, on its standard reading, a thesis about thoughts and concept possession and not, or not directly, a thesis about semantics or mental content (Burge 2007b, pp. 155-156). It follows that the considerations here presented must be set distinctively apart, and are arguably independent, from considerations in favor of a particular theory of (direct) reference or meaning of artifactual terms (e.g. Putnam 1975; Kornblith 1980, 2007). The corresponding arguments to

${ }^{5}$ See my paper (Verdejo 2013) for a possible theoretical articulation of antiindividualist views compatible with Fregeanism. 
be discussed in relation to epistemic privilege are also of a fundamentally different sort (see also fn. 8).

Let us return to the notion of epistemic privilege. Thomasson's literal word is, I submit, not only ambiguous between claims 1) and 2) above. In addition, it is not entirely clear which cases are the central cases for the assessment of the view that "makers are guaranteed certain forms of epistemic privilege about the natures of the artifactual kinds they create" (Thomasson 2007, pp. 65-66). Two possibilities come readily to mind. The first concerns cases of creation of already existing artifacts and kinds of artifacts. The second candidate turns on cases of original creation or invention. ${ }^{6}$ Since, again, I am trying to skip exegetical wrangles, I propose to concentrate on the latter case. The reason is that original creation provides the strongest intuitions in favor of the claim that authors of artifacts cannot be wrong, or at least not substantially wrong, about the kind of things they create.

Thus, summing up, for whatever object $O$ and author $A$, the thesis that I will be critically examining in what follows is Epistemic Privilege (EP):

If $O$ is a genuine artifact originally created by $A$, then $A$ has a substantial concept or knowledge of $O$ to the effect that this substantial concept or knowledge determines (at least) the sort of thing $O$ is.

Once they are explicitly stated, it is noteworthy that, on the face of it, there is no obvious reason why the compatibility of (EP) and (AI) should be discarded on the spot. On the one hand, it has been argued - and indeed the most faithful adherents of the thesis would be ready to defend - that (AI) is compatible with certain sorts of epistemic privilege, namely, the ones consisting of the privileged knowledge of or access to the contents of our thoughts (e.g. Burge 1988; Falvey and Owens 1994; Sawyer 2002; see however fn. 3). On the other hand, to acknowledge that there are external factors partially determining our own thoughts and concepts is not obviously to admit that the external factors are always operative -in the light of relevant exceptions - or to deny that one has privileged knowledge even when those external

\footnotetext{
${ }^{6}$ Both kinds of case are considered in Thomasson's (2003, 2007) work but she only commits herself explicitly to the view that the "privileged epistemic position only applies to makers (conceived broadly)" (Thomasson 2003, p. 602).
} 
factors are precisely operative: the target privileged knowledge may concern precisely the part allowed by the "at least in part" caveat featuring in (AI).

These considerations to the contrary notwithstanding, in the next Section I set myself the task of introducing a particular science fiction story based on (AI). This story and other easily conceivable analogues illustrate the kind of situation that is a perfect counterexample to (EP).

\section{The Story}

At least since Putnam (1975), discussion on anti-individualism or externalism has often involved concepts of artifacts. Here is an adaptation of a case originally introduced by Burge (1986).

Let us imagine a community CM that is exactly like our actual community except for one thing: in CM there are no sofas, and nobody ever thought about the thing that in actual communities we refer to with the term "sofa". At some (arguably important) point in CM's historical evolution, a member of CM, let's call her Caroline, begins to turn over in her mind the idea that there could be, even if no-one has ever thought of it, a piece of furniture meant for sitting, one which is more comfortable than chairs or benches, and bigger than armchairs and poufs. We can imagine Caroline becoming increasingly obsessed by her new idea, pursuing it secretly in her mind, drawing some preliminary designs of the new object, and, finally, decidedly engaging in the project of producing an instance of it for the first time. After some hard months of work, Caroline succeeds in making something that fits her conception, and creates a perfect instance of what we would, in our actual communities, undoubtedly call a "sofa". In addition, Caroline actually decides to call it a "sofa". Unexpectedly, the creative process has severely undermined Caroline's health. Ironically, she is about to die before she can explain her creation to any other member of her community. At the brink of death, she writes on a piece of paper "This is a sofa. It is made or meant for sitting". Exhausted, she puts this note on her creation, and dies.

As in many other anti-individualistic thought experiments, the story I am telling requires comparing two situations. In the first situation, Caroline's community, call it CM1, reacts as one would expect. When the members of CMl first find out about Caroline's invention, they read the note and take it literally. The virtues of the new artifact are predicated around CMl. An instance of the new 
artifactual kind "sofa" ends up occupying the vast majority of CMl's living rooms, usually just in front of CMl's TVs. The usual truisms about sofas hold in CMl. In this situation, Caroline, God bless her, has undoubtedly created a sofa.

Now, let us imagine a second counterfactual community, call it CM2. We can further imagine CM1 and CM2 being identical in all respects before Caroline's invention is known. However, in CM2, perfidious roundabout thinkers are the ones first acquainted with the thing they call "sofa". Much debate and deliberation follows. Finally, in spite of her note, it is decided that Caroline"s "sofa" is not really made or meant for sitting. On the contrary, in an overwhelming consensus, members of CM2 judge that the thing they call "sofa" is a work of art or religious artifact. We can further imagine members of CM2 bringing Caroline's "sofa" into a prestigious museum and an entire school of artists making reproductions of this object for public exhibition. In the counterfactual situation of CM2, and even if they use the form of words "sofa" to refer to Caroline's creation, there are no sofas. That is, in C2 there are no items of furniture of the sort Caroline had in mind. Many of the new instances of "sofas" would collapse under a person's weight. Let us call the relevant objects "safos". In CM2, there are no sofas but there are lots of safos. It follows from this that, in CM2, Caroline did not create a sofa at all. She created an instance, indeed the first paradigm instance, of a safo.

What Caroline's story shows is that it is plausible, and indeed conceivable, that the maker of an object $O$, even the first maker of an object $O$, is substantially wrong about the sort of thing her creation is. In the counterfactual situation CM2, Caroline believes she has created a certain sort of piece of furniture whereas she in effect has created a sort of artistic product. In this scenario, Caroline is wrong, and even substantially wrong about the sort of thing she has created. Of course, this conclusion appeals to and is therefore entirely dependent on the correctness of anti-individualism. In particular, it is crucial for this argument that one acknowledges that the relations subjects bear to their (physical or social) environments are (at least partially) constitutive of the concepts they have (Burge 1979, 1986, 2007b). If this assumption holds, Caroline has no sofa-concept. For Caroline to have a sofa-concept there should have been sofas in the environment of CM2, but there are none. It follows from this that CM2 is not a situation in which Caroline has creative intentions involving the concept sofa. More precisely, in CM2 Caroline's case is not one in which she believes, correctly, that she has created a sofa and the community mistakenly takes her to have created a safo. 
If anti-individualism is true, CM2 is, quite differently, a situation in which Caroline thinks wrongly of the first safo that it is made for sitting. ${ }^{7}$ The reason is that Caroline's actual thoughts or attitudes are (at least partially) determined by her social environment. In Caroline's social environment there are no, and there have never been any sofas. In sum, if anti-individualism is correct, (EP) above has to go. ${ }^{8}$

Remarkably, the proposed thought experiment appeals to a historical or diachronic notion of thought-determining environment, in a way that is not so manifest in other anti-individualistic thought experiments. In particular, the nature of Caroline's case requires us to know some substantial details of the evolution of her environment after her death in order for us to determine which concept she actually has, and hence, which object she actually has created. Note, however, that this is a natural and plausible consequence of the fact that antiindividualism appeals to social environments and communities, which are patently subject to historical evolution. Note, further, that to say that Caroline's relevant environment goes beyond Caroline's death is nothing like the claim that Caroline has no (determined) concept until some things happen in her environment. The relevant environment, even if changing or unexpected, is there all along to determine Caroline's thinking. On the simple form of anti-individualism I am proposing, Caroline's environment is a safo-environment in CM2 and

${ }^{7}$ Compare with Burge's celebrated arthritis case (Burge 1979). The actual situation described by Burge is not a situation in which the subject thinks correctly that she has a different disease, say, tharthritis in her thigh (and is therefore misinterpreted by her community as believing that she has arthritis in her thigh), but a situation in which the subject believes, wrongly, that she has arthritis in her thigh. The reason is that, in actual situations, in actual environments, there is no tharthritis (i.e., there is no disease that is a disease of both joints and thighs). A relevant difference in environment is, in anti-individualistic settings, ipso-facto a difference in one's conceptual repertoire and therefore a difference in one's beliefs and knowledge.

${ }^{8}$ Note that Caroline's situation does not involve a counterexample to (EP) of the sort considered and responded to by Thomasson (2007, pp. 64-69). Firstly, the focus here is conceptual and not semantic: Caroline's distinctive situation concerns the concepts that figure in her intentions, not merely the meaning of the terms she uses to express those intentions (cf. Kornblith 1980, 2007). Secondly, Caroline's case is no objection to (EP) because "it is always open to doubt whether any particular individual really is a maker, or any particular object really $i s$ an artifact or really does belong to any particular artifactual kind" (Thomasson 2007, pp. 67-68, her emphasis; cf. Putnam 1975, pp. 242-245). Caroline's case is one in which we know who the maker is, and we know what the target artifact is. It is just that Caroline is not the maker of the sort of thing she thought she was. 
hence she has the concept safo (likewise, mutatis mutandis, in CM1 regarding the concept sofa). This is so independently of whether she or anybody knows or expects it to be so (see also discussion in Section 3 and fn. 11).

Before conceding the point of the thought experiment, (EP) defenders may object that in CM2 Caroline is no longer the creator of safos. On this reading, the creators of safos would be Caroline and the group of people who first met Caroline's work. If the case were interpreted as a case of collective creation or authorship, the argument would go, a form of (EP) might be restored for the members of this group. However, please note, even if the case obviously requires that the group of people first acquainted with the work in CM2 have lots of beliefs and intentions involving the concept safo, none of these beliefs and intentions seem plausibly creative beliefs and intentions, that is to say, beliefs and intentions with the purpose of creating an object - as opposed to beliefs and intentions devoted to interpreting someone else's creation. On the other hand, it would seem that this maneuver fails to rescue a substantive form of (EP), since the candidate (collective) authors would include in this case Caroline herself, who is, as defended, actually wrong, and even substantially wrong, about the sort of thing she has created.

Once faced with these considerations, several strategies seem open to the defenders of the epistemic privilege of artifact makers. First, they can bite the bullet, and accept that anti-individualism forces them to concede that, in some cases, authors of artifacts can be substantially wrong about the nature of the objects they create but defend that there is still some sort of epistemic privilege, one that is not correctly stated along the lines of (EP). Caroline, someone could argue, is still in possession of some epistemic privilege concerning safos in the counterfactual situation of CM2. For instance, it may be claimed that Caroline has substantial knowledge about the shape, the physical structure or the materials adequate to safos. ${ }^{9}$ Alternatively, Caroline may be claimed to possess the relevant capacity to single out safos in thought. Caroline's concept individuates the right safo-sort of entity.

${ }^{9}$ As an anonymous referee points out, there are many things about the shape, structure and materials adequate to safos that Caroline does not know, precisely because she believes, wrongly, that safos are meant for sitting. However, it seems nonetheless correct to suppose that Caroline in CM2 would know some substantial features of safos (e.g. that they have seats, backs or legs and must be made of certain solid materials), the ones that would plausibly be required for having safo-thoughts in the first place. 
It seems to me that the kind of knowledge attributed to Caroline according to this strategy would be just right. Caroline, no doubt, would meet a certain knowledge condition. Arguably, this knowledge condition would be necessary for Caroline to be attributed the concept of a safo, and hence, to be a safo-creator. However, please note, there seems to be simply no basis for saying that Caroline's kind of knowledge in this context constitutes a sort of "epistemic privilege". In particular, the requirement that Caroline must know certain ( $X$-individuating) properties for thinking about an object $X$ arguably holds across the board, independently of whether $X$ is or is not an object Caroline has created. The attribution of epistemic privilege along these lines makes the attribution explanatorily idle for the identification of an epistemic condition distinctive of $X$ 's makers qua makers. Indeed, everybody can be considered to have this sort of "epistemic privilege" regardless of whether the concepts in question are of artifact kinds or of natural kinds. That is to say, this kind of "epistemic privilege" applies to any $X$-thinker, for any $X$ whatsoever, and hence becomes an idle label, a gratuitous add-on in the characterization of a maker's epistemic situation in relation to artifactual thinking. Thus, we have just met one of the horns of the fatal dilemma that the defender of epistemic privilege for artifact creators faces. If formulated in terms other than (EP), to say that artifacts" creators have "epistemic privilege" is just to use an explanatorily idle labeling.

A more promising strategy for the defender of the epistemic privilege of authors of artifacts in relation to the artifacts they are authors of would apparently be to stick to (EP) and then try to undermine the view that the anti-individualistic argument I have presented goes through. Since I am assuming the truth of anti-individualism, the strategies available to the defender of (EP) should concentrate efforts in showing that artifact creation constitutes some sort of exception to the general anti-individualistic standpoint. More precisely, the considerations offered by the defender of (EP) must be devoted to showing that Caroline did create a sofa after all. The defender of (EP) is therefore committed to disputing that Caroline has, at least initially, created a safo in the counterfactual situation CM2. Rather, Caroline might be conceived to have in any case created a sofa, an object that is eventually misinterpreted to be a safo. This is a redescription of the case consistent with (EP): Caroline always knew (in a privileged way) what she was creating and therefore had a substantive, artifact-determining concept of sofa. What happens is that Caroline's community gets it wrong about Caroline's creative intentions. The 
intuitions underlying such a redescription are strong. The defender of (EP) would seek for a reading of anti-individualism that makes it compatible with the redescription.

This is, as the reader may note, the crux of the discussion here presented. If advocates of (EP) cannot satisfactorily motivate the view that anti-individualism does not apply to cases of artifactual creation, then the prospects for such advocates are meager. Indeed, if the foregoing strategy fails, and if anti-individualism is assumed to be true, there seems to be no serious choice but to abandon the thesis of epistemic privilege of artifact makers. Let us begin to address this issue in a new section.

\section{The Demise of Epistemic Privilege for Artifact Makers}

So then, can the defenders of (EP) satisfactorily motivate the view that anti-individualism does not apply in Caroline's case? There seems to be four ways in which such a motivation can be pursued. I will discuss three of them in this section. The last one will be the topic of the fourth and final section. As we shall see, none of them succeeds.

First, defenders of (EP) may reject the applicability of antiindividualism in the cases of artifact creation because, in a very clear sense, they involve no reliance on community standards or deference to experts in the community. Thus, friends of (EP) would appeal to the fact that creative processes are special in a way that makes them immune to the general anti-individualistic credo. They may argue that success criteria for artifactuality are actually stipulated by the maker of the artifact. This is precisely the position at which Thomasson seems to gesture in the following passage:

since in order to make an artifact of any properly artifactual kind, the maker must intend to make something of that kind, she can know that if she has made any kind of artifact, she has made a $K$, and she can "know" what it takes to be a $K$, not in the sense that her beliefs correspond to an independent reality, but rather in the sense that she is the one who stipulates this by establishing success criteria for her activity. (Thomasson 2007, pp. 60-61, her emphasis.)

There is a sense in which the line of argument presented here would be exactly right. Understood in this way, Caroline's situation is consistent with the truth of anti-individualism as standardly conceived. Thus, if Caroline were not disposed to accept the community's authority as regards the (content of the) concepts with which she thinks 
of $X$ or as regards (the meaning of) the terms with which she expresses her thoughts, anti-individualistic individuation of such concepts and terms would certainly not be in force. The communal context would in that case be irrelevant for the proper individuation of Caroline's attitudes or concept of the thing she has created.

Note, however, that this is a very thin basis for grounding (EP). The reason is that (EP) is putatively a property of artifact's creators, qua creators. In other words, (EP) is supposed to be a distinguishing or defining phenomenon for the makers of artifacts regarding the artifacts they create. In this context however, Caroline's epistemic situation regarding the $X_{\mathrm{s}}$ she creates would be of exactly the same sort as the one concerning the $X \mathrm{~s}$ she does not create. After all, if one does not accept the community's dictum regarding any of one's concepts or terms, then one can claim to have epistemic privilege about any concepts and terms independently of whether these are concepts or terms of artifacts one has created. Indeed, one can claim never to be in error about such concepts or terms because one is the ultimate authority that fixes their nature. It follows from this that, even if the stipulative view were correct or coherent, it would not capture a defining or distinctive epistemic property of artifact's authors, qua authors or creators.

Nonetheless, friends of (EP) may insist that, unlike other nonartifactual cases, all cases of artifact creation are stipulative as a matter of principle and are therefore safe from the clutches of antiindividualist scenarios. However, the intuition pump for (EP) does not seem to work anymore at this point. If anti-individualism is true, it is hard to see why it should not apply to artifactual concepts, even to artifactual concepts of the first creators of artifacts. Note that defenders of (EP) are in a very bad dialectical situation: they need to make plausible the idea that all and every case of artifactual creation is stipulative. Ironically, there seems to be only one way in which this can be done: sheer and question-begging stipulation. For one thing, it is part and parcel of anti-individualism that situations of acceptance of the community standards, when these standards do not fit one's own understanding, are the rule rather than the exception and hence that cases in which anti-individualism applies "appear to be legion" (Burge 1979, p. 121) or constitute "pervasive and inevitable phenomena" (p. 132). It is therefore very hard to accept that the whole and indefinitely large class of artifacts and artifactual concepts can escape in every case the anti-individualistic consequences by appeal to stipulations. For another thing, it is not only that it is hard to justify the exclusion of anti-individualism for artifactual concepts by 
appeal to stipulations. In addition, anti-individualism, or something playing its role, is arguably required for a correct understanding of artifact creation itself. Roughly, if all there is to a subject's creating an instance of $K$ is that this subject stipulates, in Thomasson's terms, "what it takes to be a $K$ ", it is hard to see how artifacts can be other than purely idiosyncratic. And, of course, everybody agrees that artifacts should not be understood as having a purely idiosyncratic or subjective character. More precisely, everyone agrees that the mere (stipulative) intention to create an $X$ (say, a piece of furniture) is not enough for actually creating an $X$. Conditions for successful realization of creative intentions need also be fulfilled (see e.g. Bloom 1996, p. 10; Hilpinen 1992, pp. 64-65; Thomasson 2003, p. 598). But then, apart from, I suppose, appeal to a Platonist realm of artifactual kinds, if such there be, the only way in which the idiosyncrasy of artifacts can be regulated is by appealing to some existing public criterion for artifactual concepts and instances of those concepts. ${ }^{10}$ Anti-individualism provides just that criterion. It is in the essence of anti-individualism to suppose that idiosyncratic individualistic properties, be they intentional, neurophysiological, introspective or functional, are not sufficient to provide correct concept individuation, and a fortiori, correct artifact concept individuation. This is one of the reasons why, according to anti-individualism, the objective, social or environmental dimensions of concepts are taken to be (at least partially) constitutive of concepts.

In sum, the prospects of (EP) are meager if they are articulated in terms of maker's stipulations. Mental experiments like the one presented here, together with the wide scope of anti-individualism, provide powerful reasons to suppose that, granted the correctness of antiindividualism, artifact makers may fail to have a substantial concept or knowledge of the (sort of) artifacts they create. The explanation of this fact is that, such concepts are, according to anti-individualism, partially determined by the relations a subject bears to her social or physical environment. It is therefore hard to see that, in the cases

${ }^{10}$ This is also in accordance with Bloom's considerations to the effect that the problem with the idiosyncrasy of the madman that describes a pile of dust as the successful result of an intention to create a chair, or of the child who calls a disk of clay "a cup" is that "[creative] intentional attribution might require significant conceptual overlap" (Bloom 1996, p. 20). Clearly, the same conceptual overlap would be required in cases which involve strictly novel artifacts. The madman might describe the pile of dust as being a time machine, or the child could call the disk of clay a "laser gun". The present point is that the required conceptual overlap is very much guaranteed by the constraints imposed on artifactual concepts and intentions by the public and non-individualistic (social or physical) environment. 
under consideration, anti-individualism does not hold. Furthermore, there is a good reason not to exclude - and even to generalize - the application of anti-individualism in the cases of (original) artifact creation. The reason is that anti-individualism provides a solid route to preventing intolerable multiplication of purely idiosyncratic artifacts and artifactual concepts. Anti-individualism constitutes the kind of constraint that would articulate precisely the thesis that all intentionalist approaches to artifacts share, namely, that it is not enough to have an intention to create an $X$, and even to do something with the intention to so creating an $X$, in order to actually create an $X$.

So much for the first strategy. Supporters of (EP) may wish to argue in quite different terms. They may contend that, although it is true that anti-individualism requires us to conclude that Caroline has created a safo in CM2, Caroline has also created a sofa in that community. Thus, one may take Caroline to have created a sofa at a certain moment in time, roughly at some point before her death. At that point, the anti-individualist analysis would lack a suitable environmental context upon which to assess Caroline's creation. Caroline's work fits her own intentions and is conceived by her as serving and is in effect ready to serve a given (sitting-)purpose. Caroline's work is furthermore potentially a work in a community that accords with Caroline's understanding of the thing she has created. On this interpretation, Caroline has created a sofa, and only afterwards, when the relevant communal standards of CM2 hold, is the object she has created somehow transformed into or else further interpreted as being a safo. If this redescription of Caroline's case is sound, (EP) seems to be rescued.

In a similar vein, one could argue that Caroline's case is analogous to a case of creation as a result of subsequent intentions, a phenomenon also known as exaptation or minimal creation. According to this view, the creation of a safo in the counterfactual situation of CM2 is just the result of, as it were, superimposing a novel intention on Caroline's original one. This would bring safos together with other sorts of common artifacts such as pennies that are used as pawns and baseball bats that are used as weapons (cf. Bloom 1996, p. 18). Again, if some such redescription of Caroline's case is applicable, then Caroline seems to have created a sofa, even if this sofa is, after the woman dies, considered to be a safo. So we might stick to (EP) after all.

But, on reflection, not really. For adopting such a redescription of the anti-individualistic scenario is just to dismiss anti-individualism on the spot. To repeat, I am assuming the truth of anti-individualism. The defender of (EP) needs to successfully motivate the view 
that anti-individualism, even if true, does not hold in Caroline's kind of case. But the considerations just seen, that is, considerations to the effect that Caroline has created a sofa and (at a certain point) also a safo are simply against the spirit and the letter of anti-individualism. The one single thing that Caroline needs in order for it to be intelligible that she creates a sofa in the first place is that there are any sofas around in her environment. But that is precisely the thing she cannot get, if she is in CM2.

Let me put the point differently. Following Hilpinen (2008), our evaluation of a creative process for an object $X$ can be taken to consist of the evaluation of the relationship between an author's conception or intended character of $X$, the purpose for $X$, and the actual character of $X$. No doubt, at a certain moment roughly before her death, Caroline's creative process is positively assessed with respect to the fit of the intended character of $X$ and a certain purpose for $X$, namely, the purpose of being used for sitting. However, the creative process should also be assessed with respect to the fit between the conception or Caroline's intended purpose for $X$, and the actual character of $X$. When evaluated in this respect, Caroline's creative process regarding sofas - that is, our answer to the question: "has Caroline succeeded in creating a sofa?" - must be negatively assessed because Caroline's actual world is, by assumption, a world where there are no (there was no and, for all we know, there might not ever be any) sofas. In other words, the defender of (EP) needs to make plausible the idea that, in a way consistent with anti-individualism, at some point in Caroline's actual community (viz. CM2), there was some sofa. But the only way in which we can accept that is by considering Caroline's individual, intended features to wholly determine her creation and the corresponding concept before she dies. That is to say, the only way in which we can make sense of Caroline's creating a sofa is by denying anti-individualism. Thus, all that can be said, really, is that Caroline at some point believed, wrongly, that safos were meant for sitting. The fact that Caroline's creation is the potential creation of a sofa does not make it the creation of an actual sofa. And it is hard to deny that an essential part of the evaluation of the creation of $X$ is the actual character of $X$. The actual character of the object Caroline has created is the actual character of a safo, an object she has mistakenly thought to serve the purpose of sitting. ${ }^{11}$

\footnotetext{
${ }^{11}$ This conclusion is further supported via reflection on what it would take for the defender of (EP) to fill in the details of a story in which Caroline creates a sofa and a safo. Which concept and which intentions should we attribute to Caroline?
} 
The situation for the supporter of (EP) is even worse than the above considerations suggest. The reason is that one does not even need to appeal to an anti-individualistic description of Caroline's case in order to justify the claim that her creative intentions regarding sofas in CM2 are not satisfactorily realized in a fundamental, crucial respect. As some authors have emphasized, many artifacts (Thomasson 2014) and even the whole class of artifacts properly so-called (Dipert 1993) have a fundamental public dimension. In other words, among the fundamental intentions for the creation of $X$ one finds the ones that make "the creation be subject to certain norms, in the sense that it be recognizable as something that is to be treated, used or regarded, in some ways rather than others" (Thomasson 2014, pp. 51-52, her emphasis). Of course, as always, in order for $S$ to create $X$ it is not only required that $S$ has such intentions concerning public norms for $S$ 's creation. It is in addition required that this intention be realized satisfactorily. But then, it is clear that even if we reject anti-individualism and find it adequate to attribute to Caroline intentions containing the concept sofa (at some point before her death), Caroline's intentions regarding the norms of use of her invention dramatically fail. There is no-one that recognizes Caroline's putative intentions regarding the normativity of her creation and, hence, no trace of willingness in Caroline's community to respect such normativity. It follows that, even by purely intentionalist lights, Caroline could not possibly have created a sofa in CM2. ${ }^{12}$

Does it make any sense to say that Caroline had the intention to create (and the concept of) a sofa before her death and an intention to create (and a concept of) a safo after her death? Alternatively, is it really intelligible to describe Caroline as having an ongoing amalgam intention to create (and an amalgam concept of) a sofa and a safo before and after her death? How would this square with the fact that anti-individualistic thought experiments "cannot be glossed as involving reference shifts in context-dependent thoughts" (Burge 2007b, p. 152; see also Burge 1982, and Putnam 1996) and thus that Caroline cannot be said to have the same (context-) dependent concept in CMI and CM2? These hard questions are simply avoided if we stick to a simple form of anti-individualism, one according to which Caroline's concept depends on her environment. On this reading, Caroline possesses just one (non-indexical) concept all along, before and after her death - a safo concept in CM2 and a sofa concept in CM1. Of course, as noted above, the relevant (thoughtdetermining) environment in Caroline's case goes beyond her very existence. But that is a natural consequence of the fact that anti-individualism appeals to social environments that are subject to historical evolution.

${ }^{12}$ Thomasson (2014) may mark, I dare to say, an important change of heart in Thomasson's work. Earlier, she was happy to assume that, unlike institutional objects, artifacts "need not be the products of collective intentions nor depend on collective beliefs" (Thomasson 2003, p. 599). Now, she contends that "the need 
In short, (EP) is not defensible by appealing to a twofold sort of creation. To all intents and purposes, Caroline does not and could not have created a sofa, and hence there is no room for her having a substantively correct concept of the sort of thing she has actually created.

Let us go now into a third alternative strategy. The defender of (EP) may find it hopeful to argue as follows. Caroline, true, does not and could not possibly have created a sofa. However, let us imagine a slight variation of the case. In particular, what if Caroline does not really die? What if she simply suffers a critical accident so that she is in a coma for a large period of time? After many years, she could wake up and see what happened to her creation. What would Caroline say in this case? Would not she be willing to explain to other members of her community that her invention was, in effect, made or meant for sitting? Imagine that she possesses the stubbornness of other brilliant creators. Would not she insist on the appropriateness of her original conception?

Another way of putting these considerations is as follows. For any subject $S$, creation $X$, and environment $E$, how would a rational $S$ react in the light of unexpected information about $X$ and $E$ ? As Schroeter has argued at length (Schroeter 2008), ${ }^{13}$ the correct answer to this question seems to be that rational representational practices in these contexts may be used to give further support to antiindividualism. In the just imagined scenario, the anti-individualist would argue, if Caroline came back to the ordinary life in CM2, she would very likely refine (and be rationally required to refine) her own representational practices regarding the $X$ she created in the light of the new and highly surprising information about her (social) environment. It is hard to see how Caroline could rationally dispute the claim that she was the first maker of a safo, even if she thought to have created something meant for sitting. Arguably, Caroline's rational reconstruction would very likely assign different

for individual intentions alone doesn't seem to fully capture what it is to be a member of one of our standard, extant artifactual kinds" (Thomasson 2014, p. 55). This intentionalist view, which is independent from anti-individualism, seems to put much fatal pressure on the thesis of epistemic privilege.

${ }^{13}$ Schroeter (2008) provides a new argument for anti-individualism based on ideal, fully informed and rational representational practices. The fundamental idea is that first-person rational representational practices are committed to disambiguating dejure co-referential concepts when they are discovered (in e.g. switching scenarios) not to be actually co-referential (see Schroeter 2008 for details). We can apply Schroeter's approach in the present context by asking what would be rationally required of Caroline if she knew what happened to her creation. 
representations to what she actually created (a paradigm instance of a kind of religious artifact), and that what she mistakenly thought she had created (a paradigm instance of a piece of furniture). She might even begin to pursue the creation of a genuine sofa-sort of thing. If successful, her creation would constitute a new artifact in Caroline's community. However, note that this would not change a thing with respect to the way Caroline should rationally conceive her first creation. Caroline would still be, even by her own best judgment, the first maker of a safo, an artifact that she mistakenly took to be a piece of furniture. On the anti-individualist interpretation, Caroline would be rationally committed to refining her own representational practices about the thing she created (and even rationally obliged to do so) after finding out about her surprising social environment. Therefore, the third imagined strategy for the defender of (EP) also fails.

A final line of argument may be appealed to in the defense of (EP). It might be claimed that to reject (EP) amounts to rejecting the intentional character of artifact kinds. In other words, the rejection of (EP) may be taken to go against the largely unchallenged Authorship (A). To recall, for any $O$ and $A$ :

\section{(A)}

If $O$ is a genuine artifact, then there is an $A$ who has (or has had) the intention to create something of the $O$-sort.

It must be noted that, even if perhaps largely unchallenged, (A) is not universally shared. Theorists may appeal to several cases, including cases of serendipity or accidental creation of new artifacts, in order to show that the essence of artifactuality may (eventually) go beyond or be independent of human intentionality (e.g. Elder 2007, Vaccari 2013). Nonetheless, it would seem a remarkable fact if the defenders of (EP) could not appeal to (A) for dialectical purposes in this context, even conceding that it is true.

\section{Mind-Dependent and Intentional Artifacts}

Thomasson $(2003,2007)$ presents her views on epistemic privilege as being a natural (epistemic) consequence of the intentional character of artifacts and artifactual kinds. This intentional character is captured in (A) and it is closely related to certain forms of metaphysical and semantic dependence between artifacts and intentions to create them. If (A) is correct, then, metaphysically, it would seem that 
artifacts cannot exist without somebody's having intentions to create them. From a semantic point of view, if (A) holds, artifacts apparently cannot be referred to, or their extension cannot be determined, regardless of the intentions of their creators. This results in a metaphysical and semantic mind-dependency of artifacts and artifactual kinds. Unlike natural kinds, someone could argue, there can be no artifacts or no reference to artifacts if there are no proper beliefs or intentions about such artifacts. However, it was implicit in much of the foregoing discussion, and I am about to argue in what follows, that the intentional character of artifacts and artifactual kinds does not suffice to grant any form of epistemic privilege. Since alternative formulations do not make the alleged "epistemic privilege" anything more than an idle label, what I contend is that the intentional character of artifacts is not sufficient to support (EP). If sound, this point would be good news since, as I have been arguing, (EP) is, if we assume the truth of anti-individualism (AI), ${ }^{14}$ quite certainly false. And, on the face of it, (A) or some thesis in its vicinity seems intuitively correct. If we do not wish to threaten (A) with a perfect instance of modus tollens, we had better make explicit why (A) does not entail (EP).

It is however quite easy to see why. (A) is completely safe from the demise of (EP). What (A) claims, to repeat, is that no object is a genuine artifact if it is not the result of a creative intention. More precisely, there is no artifact if there is no maker or makers of such an artifact. In addition, to be an artifact maker one has, at a minimum, to have intentions about the artifact and, to have such intentions, one has to possess the concept of the artifact. As I noted at the outset, this is to say that (A) entails Possession (P) for any artifact $O$ and author $A$ :

\footnotetext{
${ }^{14}$ Contrary to what I have been assuming all along, defenders of (EP) may of course refuse to acknowledge the truth of anti-individualism. No doubt, one may eventually have to choose between anti-individualism and epistemic privilege at least in the context of artifactual creation. So be it. But note that it is hard to see what sort of arguments could motivate this theoretical alternative. In particular, it seems to me obvious that anti-individualism does not involve the sort of indeterminacy signalled by those who appeal to the so-called "qua problem" to propose a nonpurely causal theory of reference (e.g. Thomasson 2007, Devitt and Sterelny 1999). The case of Caroline, and other cases of its kin, seem to raise no problem regarding what sort of thing Caroline creates or refers to (in thought). It is just that the sort of thing she creates or refers to (in thought) may vary, unbeknownst to her, along with her environment.
} 
If $O$ is a genuine artifact, then there is an $A$ who has (or has had) the concept of $O$.

Thus, the question of whether (A) can be true even if (EP) is false boils down to the following one: can we make sense of $(\mathrm{P})$ being true and, at the same time, an author $A$ being seriously wrong about the nature of $O$ ?

We certainly can, and we arguably should. Consider Caroline again. Anti-individualism shows that Caroline's intentions in the process of creating her $O$ are constitutively dependent on her (social) environment. However, precisely because Caroline's intentions are so dependent on the environment, Caroline's concept of $O$ is (at least partially) also determined by her environment. In the case of CM1, such a concept is the concept of a sofa. In the case of CM2, such a concept is the concept of a safo. The important point for present purposes is that, no matter which scenario one chooses (viz. the one in which Caroline creates a sofa or a safo) Caroline always has the right sort of intentions concerning her creation. In both scenarios, it is true that there could not have existed an artifact $O$ (viz. a sofa or a safo) without someone (viz. Caroline) having the intention to create an $O$ (viz. the intentions involving the concepts sofa or safo). However, whereas in CMl Caroline gets it right about the thing she creates, in CM2 she gets it substantially wrong. Caroline's case is, on the anti-individualistic reading, precisely a case in which the first creator of $O$ may be substantially wrong about $O$ in spite of her having the concept of $O$.

Note that to subscribe to this anti-individualistic view is perfectly consistent with a mind-dependence thesis regarding metaphysical and semantic dimensions. Semantically, the failure of (EP) is perfectly compatible with the view that one cannot be said to refer to an artifact $O$ without somebody's intentions fixing (together with the environment) the extension of the term for $O$. Metaphysically, the antiindividualistic view here expounded is also compatible with holding that, necessarily, for $O$ to be an artifact there has to be an intention to make an $O$. From all this it does not follow that one has, in addition, to be immune from error or have privileged knowledge about the thing one has created, as Caroline's example clearly shows.

Finally, this provides just the coup de grâce against any notion of epistemic privilege, be it interpreted in terms of (EP) or in some other terms: the mind-dependent character of artifactuality that (A) 
guarantees is perhaps the only one really needed to draw the thick, intuitively plausible line between artifact and natural kinds. However, (A) is much weaker than, and clearly independent from, a thesis about epistemic privilege. Indeed, one can hold to (A) while firmly denying (EP) or some other thesis regarding the privileged knowledge of authors. This is all to the good since, as I have been arguing, (EP) is almost certainly false if anti-individualism is true.

The fascinating world of artifact and artifact creation may make us believe that we, imperfect mortals, have something of the omniscient power of God regarding the things we create. It seems however that anti-individualism would disappoint us on this score. If anti-individualism is true, there is, to all appearances, no epistemic privilege for artifactual creation, not even for original and novel artifacts. 15

\section{REFERENCES}

Baker, L.R., 2004, "The Ontology of Artifacts", Philosophical Explorations, vol. 7, no. 2, pp. 99-111.

Bloom, P., 1996, "Intention, History, and Artifact Concepts", Cognition, vol. 60, no. 1, pp. 1-29.

Brown, J., 2004, Anti-Individualism and Knowledge, The MIT Press, Cambridge, Mass.

— , 2000, "Critical Reasoning, Understanding, and Sef-Knowledge", Philosophy and Phenomenological Research, vol. 61, no. 3, pp. 659676.

Burge, T., 2010, Origins of Objectivity, Oxford University Press, Oxford. - 2007a, Foundations of Mind, Oxford University Press, Oxford.

, 2007b, "Postscript to "Individualism and the Mental" ", in Burge 2007a, pp. 151-191.

— 1988, "Individualism and Self-Knowledge", Journal of Philosophy, vol. 85, pp. 649-663.

${ }^{15}$ Several improvements of this paper have been made thanks to the comments and suggestions of two anonymous referees for Crítica, María Muñoz, Laura Ortega, and the participants and audiences of the workshop on affordances and artifacts held at the Universidad Autónoma de Madrid (UAM), and the 2012 SLMFCE symposium on semantics and epistemology of artifactual kinds held in Santiago de Compostela. Special thanks are due to Jesús Vega Encabo, for his valuable feedback and for introducing me to the philosophical issues surrounding artifactuality. This research has received financial support from the Spanish government, via the Ministerio de Economía y Competitividad (research projects FFI2009-08828/FISO and FFI2012-35153), and from the Catalan government, through the consolidated research group GRECC (SGR2009-1528). 
Burge, T., 1986, "Intellectual Norms and the Foundations of Mind", Journal of Philosophy, vol. 83, pp. 697-720.

, 1982, "Other Bodies", reprinted in Burge 2007a, pp. 97-114.

- 1979, "Individualism and the Mental", reprinted in Burge 2007a, pp. $100-150$.

Davis, W., 2005, "Concepts and Epistemic Individuation", Philosophy and Phenomenological Research, vol. 70, no. 2, pp. 290-325.

Devitt, M. and K. Sterelny, 1999, Language and Reality, The MIT Press, Cambridge, Mass.

Dipert, R., 1995, "Some Issues in the Theory of Artifacts: Defining 'Artifact' and Related Notions", The Monist, vol. 78, no. 2, pp. 119135.

- 1993, Artifacts. Art Works and Agency, Temple University Press, Philadelphia.

Elder, C., 2007, "On the Place of Artifacts in Ontology", in Margolis and Laurence 2007, pp. 33-51.

Falvey, K. and J. Owens, 1994, "Externalism, Self-Knowledge, and Skepticism", Philosophical Review, vol. 103, no. 1, pp. 107-137.

Fodor, J.A., 2004, "Having Concepts, a Refutation of the XXth Century", Mind and Language, vol. 19, no. 1, pp. 29-47.

- 1998, Concepts. Where Cognitive Science Went Wrong, Oxford University Press, Oxford.

Goldberg, S., 2009, "Experts, Semantic and Epistemic", Nô̂s, vol. 43, no. 4, pp. 581-598.

- 2007, Anti-Individualism. Mind and Language, Knowledge and Justification, Cambridge University Press, Cambridge.

Heal, J., 2013, "Social Anti-Individualism, Co-Cognitivism, and SecondPerson Authority", Mind, vol. 122, no. 486, pp. 339-371.

Hilpinen, R., 2008, "Artifact”, in Edward N. Zalta (ed.), The Stanford Encyclopedia of Philosophy, available at: <http://plato.stanford.edu/archives/ fall2008/entries/artifact/> [11/04/2013].

—- 1992, "On Artifacts and Works of Art", Theoria, vol. 58, no. 1, pp. 58-82.

Houkes, W. and A. Meijers, 2006, "The Ontology of Artifacts: the Hard Problem", Studies in History and Philosophy of Science, vol. 37, no. 1, pp. 118-131.

Houkes, W. and P. Vermaas, 2009, "Contemporary Engineering and the Metaphysics of Artifacts: Beyond the Artisan Model", The Monist, vol. 92, no. 3, pp. 403-419.

Kornblith, H., 2007, "How to Refer to Artifacts", in Margolis and Laurence 2007, pp. 138-149.

, 1980, "Referring to Artifacts", Philosophical Review, vol. 89, no. 1, pp. 109-114.

Margolis E. and S. Laurence (eds.), 2007, Creations of the Mind: Theories of Artifacts and their Representation, Oxford University Press, Oxford. 
Putnam, H., 1996, "Introduction", in A. Pessin and S. Goldberg (eds.), The Twin Earth Chronicles, M.E. Sharpe, London.

, 1975, "The Meaning of 'Meaning'", reprinted in Mind, Language, and Reality: Philosophical Papers. Vol. 2, Cambridge University Press, Cambridge, 1975, pp. 215-271.

Rescorla, M., 2013, “Against Structuralist Theories of Computational Implementation", British Journal for the Philosophy of Science, vol. 64, no. 4, pp. 681-707.

Sawyer, S., 2002, "In Defense of Burge's Thesis", Philosophical Studies, vol. 107, no. 2, pp. 109-128.

Schroeter, L., 2008, "Why Be an Anti-Individualist?", Philosophy and Phenomenological Research, vol. 77, no. 1, pp. 105-141.

Silins, N., 2012, "Explaining Perceptual Entitlement", Erkenntnis, vol. 76, no. 2, pp. 243-261.

Thomasson, A.L., 2014, "Public Artifacts, Intentions, and Norms", in M. Franssen, P. Kroes, T.A.C. Reydon and P. Vermaas (eds.), Artefact Kinds: Ontology and the Human-Made World, Springer, Synthese Library, chap. 4, pp. 45-62.

- 2007, "Artifacts and Human Concepts", in Margolis and Laurence 2007 , pp. 52-73.

- 2003, "Realism and Human Kinds", Philosophy and Phenomenological Research, vol. 67, no. 3, pp. 580-609.

Vaccari, A., 2013, "Artifact Dualism, Materiality, and the Hard Problem of Ontology: Some Critical Remarks on the Dual Nature of Technical Artifacts Program", Philosophy and Technology, vol. 26, no. 1, pp. 729.

Verdejo, V.M., 2013, "Concept Possession, Cognitive Value and AntiIndividualism", Dialogue, vol. 53, pp. 1-25.

Vermaas, P. and W. Houkes, 2003, "Ascribing Functions to Technical Artifacts: A Challenge to Etiological Accounts of Functions", British Journal for the Philosophy of Science, vol. 54, no. 2, pp. 261-289.

Received: April 11, 2013; revised: January 22, 2014; accepted: February 6, 2014. 